\title{
The nine forms of the French Riviera: Classifying urban fabrics from the pedestrian perspective
}

\author{
Giovanni Fusco, Alessandro Araldi \\ Université Côte-Azur, CNRS, ESPACE. Nice, France \\ E-mail: giovanni.fusco@unice.fr, alessandro.araldi@unice.fr
}

\begin{abstract}
Recent metropolitan growth produces new kinds of urban fabric, revealing different logics in the organization of urban space, but coexisting with more traditional urban fabrics in central cities and older suburbs. Having an overall view of the spatial patterns of urban fabrics in a vast metropolitan area is paramount for understanding the emerging spatial organization of the contemporary metropolis. The French Riviera is a polycentric metropolitan area of $1500 \mathrm{~km} 2$ structured around the old coastal cities of Nice, Cannes, Antibes and Monaco. XIX century and early XX century urban growth is now complemented by modern developments and more recent suburban areas. A large-scale analysis of urban fabrics is carried out through the new geoprocessing protocol of Multiple Fabric Assessment (MFA). Nine families of urban fabrics, of decreasing urban intensity, are identified and correlated to the historical periods of their production. Projected in geographic space, each family stretches coherently over a whole morphological region. The spatial organization of morphological regions of the coastal cites of the French Riviera follows the same archetypical genotype, mixing concentric belts and sectors, interwoven by new connective fabrics. This data-driven bottom-up procedure is not intended to supersede traditional expert-base analysis of urban fabric. Rather, it should be considered as a complementary tool for large urban space analysis and as an input for studying urban form relation to socioeconomic phenomena.
\end{abstract}

Keywords: French Riviera, Urban Fabrics, Morphological

Regions, Urban Form Recognition, Multiple Fabric Assessment

\section{Introduction}

Recent metropolitan growth produces new kinds of urban fabric, revealing different logics in the organization of urban space, but coexisting with more traditional urban fabrics in central cities and older suburbs (Knox 1992, Ascher 1995, Levy 1999). Having an overall view of the spatial patterns of urban fabrics in a vast metropolitan area is of paramount importance for understanding the emerging spatial organization of the contemporary metropolis. However, this goal cannot be achieved without the use of spatial analysis algorithms allowing a certain degree of automatization in the geoprocessing of urban fabric.

Scientific literature in the last thirty years abounds with methodological proposals for the geoprocessing of urban form. The earliest proposals did not integrate the multidimensional character of urban fabric as defined by the traditional school of urban morphology. In order to better reflect the complexity of urban fabric analysis, Araldi and Fusco (2017) proposed the new methodology of Multiple Fabric Assessment (MFA). This paper will not go in the details of the methodological aspects of MFA but will show what empirical results can be produced on the real-world case study 
of the French Riviera, a metropolitan area of more than $1500 \mathrm{~km} 2$ in Southern France.

The paper is structured as follows. The next section will overview available methodologies for the geoprocessing of urban fabrics, highlighting a few peculiar characteristics of MFA. Section 4 will present the case study of the French Riviera. Section 5 and 6 summarize the empirical results for this case study. The former is dedicated to the analysis of urban fabrics through MFA, the latter to the overall spatial organization of morphological regions within the cities of the French Riviera. A conclusion section will summarize the research results and identify possible future developments.

\section{Multiple Fabric Assessment: Geoprocessing the Pedestrian Perspective}

The first methods of automated quantitative analysis of urban form focused on selected elements of the urban morphological system. Space syntax (Hillier and Hanson 1984, Hillier 1996) as well as authors like Marshall (2005), even if with completely different approaches, focus their analyses on the street-network morphology. Berghauser-Pont and Haupt (2010) propose a multivariate approach in the analysis of building fabric morphology. Using the elementary unit of the street block, they cross-analyze different dimensions of urban density (built intensity, compactness, open space ratio and building height) to identify typomorphologies of urban blocks in contemporary cities. Surface distribution of built up elements is also the main concern of fractal analysis of urban form (Frankhauser 1994, Thomas et al. 2007).

The concept of urban fabric, proposed by the traditional school of urban morphology offered a more comprehensive view of urban form at the micro-scale (Levy 2005). Urban fabric is the overall pattern emerging from the interplay between buildings, parcels, streets and site. The scientific community is thus increasingly proposing new geoprocessing approaches capable of integrating the multidimensional character of urban fabric using quantitative analysis and different degrees of computeraided automation.
The precise objectives of the analysis of urban form inevitably influence the selection of descriptors of urban fabric, as well as the basic units of the analysis. The many analyses focused on micro-climatic or energyconsumption issues (like Long and Kergomard 2005, Puissant 2010, Bernabé et al. 2013) find street-blocks as practical units of analysis or use a superimposed grid. The urban block was also central for the traditional analysis of urban morphologists: its historical permanence allows an easier diachronic analysis of built-up forms within it. The block is finally privileged by Gil et al. (2012) and by Giannopoulou et al. (2014) in a geoprocessing approach.

Another important phase in the geoprocessing of urban fabric are the computer-aided algorithms used to identify different empirical typologies. Pinho and Oliveira (2009) show the potential of GIS platforms to support historical analysis of urban fabric formation and transformation and to typify urban fabrics based on rigorous computer-aided measurement of form elements characteristics. Their identification of urban fabric types in Lisbon and Oporto is nevertheless carried out mainly on descriptors of street-layout, like in Marshall (2005) and no particular algorithm is used to identify the types inductively. Both Gil et al. (2012) and Bernabé et al. (2013) use k-means to inductively identify types of urban fabric using city blocks. The former apply the same method to identify types of streets, as well, integrating a few descriptors of configurational analysis; the latter apply the analysis only on city blocks. Giannopoulou et al. (2014) combine hierarchical clustering with factor correspondence analysis. Fusco (2016) uses Bayesian clustering in order to identify administrative units sharing a same subset of common features of urban form (including some key configurational parameters) and functions.

Multiple Fabric Assessment (Araldi and Fusco 2017) has been proposed to integrate several methodological innovations proposed so far. However, MFA departs considerably from many of the aforementioned works as it is centered on a completely different viewpoint. Geoprocessing methods of urban fabric 
assumed until now the urban layout observed on a plan from the analyst. MFA, as proposed by its authors, is aimed at characterizing urban fabrics as they are perceived by the pedestrians experiencing the urban space. Accordingly to this renewed perspective, spatial units are defined bearing in mind the two fundamental activities that all pedestrians implicitly or explicitly practice: walking along urban streets and looking the surrounding urban environment. The spatial units used for the analysis are defined accordingly. In so doing, MFA follows a pedestrian-centered approach which is already at the heart of Space Syntax. At the same time, MFA is not a configurational approach and aims at including all the relevant aspects of urban fabrics, like other geoprocessing methods. Within MFA, generalized Thiessen polygons around street segments, with visibility thresholds, define a new basic unit from the pedestrian point of view: the proximity band around a street segment (Figure 1). Contrary to the tradition of urban morphologists, who privilege the street-block decomposition given its link to urban morphogenesis, the focus is given to the pedestrian perspective: when standing in public space, people perceive the urban fabric on both sides of the street, not the elements within the four sides of a block.

Morphological indicators are later calculated in these street proximity bands in order to describe the built-up fabric, the street-network fabric, the parcel fabric, the site and the pairwise relations between these fundamental components of urban fabric. Proximity bands of $10 \mathrm{~m}, 20 \mathrm{~m}$ and $50 \mathrm{~m}$ are used for the different indicators. A final set of 21 morphological indicators are described in Araldi and Fusco (2017). Some of them are visualized in Figure 2 in order to show their significance for pedestrian perception.

Each street segment proximity band is described by the whole set of morphological indicators. The identification of urban fabric requires a comparative analysis of each value with those assigned to the surrounding street elements, in order to identify relevant spatial patterns. An essential phase of geostatistical analysis is thus necessary: areas of statistically significant higher and lower values for each morphological indicator must be determined. Local indicators of spatial association are used but, in order to respect the pedestrian perspective, the Local Indicators of NetworkConstrained Clusters (LINCS, Yamada and Thill 2010) are preferred: consistent patterns of higher and lower values for morphological indicators have to respect the same street connectivity that is experienced by pedestrians moving on the street network.

Finally, as already proposed by Fusco (2016) Bayesian network clustering is used to identify typical associations of the different morphological features within a given study area. Araldi and Fusco (2017) highlight how geostatistical processing is necessary before engaging in multivariate clustering. The goal of the clustering analysis is precisely to detect consistent patterns of closely connected streets showing peculiarmorphological characteristics; without preliminary LINCS analysis this result would not be attainable. Finally, Bayesian clustering differs considerably from more traditional k-means approaches: urban fabrics are identified whenever they consistently share a few common characteristics, but they do not need to be homogeneous on all the 21 features described by the morphological indicators. These characteristics are not the same when we consider different urban fabrics, and this is much more in agreement with the findings of classical urban morphology (Borie et Danieul 1984).

\section{The French Riviera Metropolitan Area}

The French Riviera is an emerging metropolitan area in Southern France (Figure 3). Once the independent Principality of Monaco is included, this area has a population of more than one million inhabitants over $1500 \mathrm{~km} 2$. This space is a unique conjunction of natural and urban landscapes: firstly, the topography, with elevation ranging from the sea level up to 1700 meters of the Prealps (passing through hills and valleys differently sloped). Secondly the socio-political and historical influences on urban development, in general, and urban planning, in particular. Traditional villages 
and suburban developments are spread around three high density urban areas. From east to west, we find: Monaco and its skyscrapers, the most densely populated sovereign nation in the world; the urban agglomeration of Nice with a regular urban grid at its core inspired by the Turin model (Graff 2000), surrounded by hilly and less tightly planned areas. And finally the urban agglomeration of Cannes-Grasse-Antibes characterized by land irregularity together with the car-centered sprawl development of the lasts 50 years (Fusco 2016). All over the French Riviera, XIX century and early XX century urban growth is now complemented by modern developments and more recent suburban areas. The combination of all these elements produces a sequence of urban centers and peripheral areas of different size and different morphology within a unique coastal conurbation stretching from the French-Italian border (to the east) to the Esterel mountains (closing the bay of Cannes to the west).

The perimeter of the study area (Figure 3) does not correspond to any administrative definition. This perimeter is in fact fragmented in several metropolitan local governments, as well as the little independent Principality. It was rather defined in order to include the aforementioned coastal conurbation, as well as most of the sprawling villages in its close hinterland.

The first goal of the analysis is thus to identify and characterize families of urban fabrics within this vast study area. Inasmuch the MFA methodology was used, the approach is inferential and data-driven: we did not want to define the different urban fabrics with expert knowledge, but retrieve them inductively from the geoprocessing and Bayesian clustering of morphological indicators. Careful expert work is then needed to interpret the results and evaluate their adequacy with domain knowledge. A second goal of the analysis is to study the spatial arrangements of urban fabric types within the metropolitan area. Can vast morphological regions be identified or is the metropolitan area a patchwork of small fragments of the different urban fabrics? In both cases, what spatial logics underpin the distribution of these morphological regions? Can consistent patterns of spatial organization be identified within the metropolitan area? What does this reveal on the morphogenesis and the functioning of the French Riviera metropolitan area?

\section{The Morphological Analysis of Urban Fabrics on the French Riviera}

The study area of the French Riviera contains almost one hundred thousand street segments. $90 \%$ of the them measure between 8 and 350 $\mathrm{m}$. When considering a $20 \mathrm{~m}$ proximity band, spatial units around these street segments have an average surface of $1670 \mathrm{~m} 2$.

MFA on these spatial units identifies nine different families of urban fabrics on the French Riviera (Table 1). These families are particularly well-defined and well separated in the mutual information space associated with the Bayesian clustering. They also have a different weight in the study area (values given in Table 1 are calculated on number of street segments and not on street segment length). The number of clusters was identified as optimal by Bayesian algorithms of cluster optimization, with the only constraint that each cluster should represent at least $1 \%$ of the spatial units in the study area, to avoid data overfitting. As they are arranged in Table 1, they make up a continuum gradient of decreasing urban character. In interpreting the cluster content, we will use the concept of "families" of urban fabrics. Clusters are often made of slightly different urban fabrics, representing synchronic or diachronic variations of a basic type (Caniggia and Maffei 1979). Sometimes similar urban fabrics can also be produced in phases of urban history which are well separated in time. They will nevertheless be included in the same family if they share the same key morphological characteristics defining the family.

The first family is the one of the old constrained urban fabrics of town-houses making up the medieval and late-medieval villages of the French Riviera. They are dense (in the sense of high coverage ratio), made up of adjoining town-houses and small buildings with a high height/width ratio on short streets that can be more or less steep but always present a high street-corridor effect channeling 
pedestrian visual field while moving. Street networks are highly connective and irregular. Street acclivity and windingness is higher in the perched villages and in the oldest citycenters. The "bastide" towns of Valbonne, Mouans-Sartout and Vallauris in the western Riviera are exceptions of street-network regularity but possess all the other defining characteristics of the family. Exceptionally, e few residential developments were produced in the last decades to replicate the urban fabrics of the old villages. The most vernacular type of urban fabric, this family accounts today for only $6.3 \%$ of street segments on the French Riviera.

The second family accounts for a slightly larger share of spatial units $(9.3 \%)$. It corresponds to the traditional urban fabrics with adjoining buildings having characterized the strong urban expansion of French Riviera cities on the flatlands from the early XVIII century until the Second World War. Buildings and parcels are bigger than in the previous family and, above all, street networks are much more regular. The highest regularity characterizes the city-center of Nice (but not its old town, mixing medieval urban fabric with early XVIII century expansions), particularly the neighborhoods planned by the Consiglio d'Ornato (the local planning body) in the XIX century (Graff 2000). Street corridor effect remains particularly important, as well as building frequency, because mega-buildings are only to be found as exceptional additions of the last decades. Sometimes, social housing projects of the last decades or new developments of high-rise buildings are also included in this family. The high-rise developments in Monaco are also exceptional within this family: their street network, although well-connected, is particularly irregular and the height/width ratio would make it a class on its own, had the $1 \%$ constrain not been applied in the cluster search.

The family of discontinuous and irregular urban fabrics mixing individual houses and bigger buildings (No.3) accounts for an additional $8.1 \%$ of the study area. Many of these urban fabrics started being developed in the late XIX or early XX century, in the form of small subdivisions or even individual self-construction. They have later undergone building infilling, addition and replacement resulting sometimes in important transformative processes. They are thus characterized by less pronounced specificities than the two previous families, as they often mix characteristics of denser traditional urban fabrics, modern discontinuous urban fabrics and even suburban fabrics.

The family of modern discontinuous urban fabrics with big and medium-sized buildings is particularly important on the French Riviera (15.5\% of the study area). These urban fabrics are particularly the product of post-war modern developments, following the blueprint of CIAM precepts. The traditional relationship between parcel, streets and buildings is often lost (Panerai et al. 1997, Graff 2013). Street networks are also relatively irregular as meshed arterial roads are superposed to more local tree-like fragments. It is true that some developments like the late XIX century gardencity of belle-époque big buildings on the hill of Cimiez (Nice) are part of this family of urban fabrics, despite their pre-modern appearance. In these neighborhoods, the discontinuity between big buildings was indeed a main departure from more traditional urban fabrics and was correlative to the project of inserting buildings in large, wooded parcels.

The next two families (No. 5 and 6) are made up of two different strains of suburban fabrics. On the French Riviera, suburbs lack the regularity and monotonous patterns typical of North-American, but also of British and other French residential urban peripheries. Land ownership fragmentation, topographic constrains and the importance of self-construction produced landscapes of particularly irregular and heterogeneous suburban fabrics over the last 50 years. Irregular, tree-like, winding street networks with numerous cul-de-sac and prevalence of individual houses with low coverage ratios are the main characteristics of all suburban fabrics in the study area. A difference can nevertheless be made between, on the one hand, the suburban residential fabrics on the hills or in the plain (No. 5), particularly important in the western section of the French Riviera, where street acclivity and area slopes are low and houses tend to be bigger villas and, on the 
other, the constrained suburban fabrics of more mountainous areas (No. 6), especially in the eastern section of the French Riviera, where steep winding roads are the norm and houses tend to be smaller. The prestigious capes (Cape d'Antibes, Cap Ferrat, Cap Martin) are strongly characterized by the first form of suburban fabrics, with exceptionally big villas and swimming-pools. Old villas and mansions from the late XIX and early XX century are here mingled with more modern villas sharing few architectural and stylistic features but contributing both to the same spatial logics of the suburban fabric. Together, these two families of suburban fabrics make up almost a third of the street-segments in the study area.

The family of connective artificial fabrics with sparse specialized big buildings (No.7) is perhaps the most peculiar urban form of the last 40 years of metropolitan development. Its quantitative importance is not huge (only $7.7 \%$ of street segments) but it is present in almost all peripheral areas in the interstices between the other families of urban fabrics. Artificial connective fabrics are usually to be found around main arterial roads, highway interchanges and roundabouts. The biggest buildings of the metropolitan area (shopping malls, factories, hospitals, air terminals, warehouses, hangars) are built along these street segments, but at a distance that is not at the scale of pedestrian movement and perception. Most of the technological park of Sophia-Antipolis, north of Antibes, is characterized by this emerging metropolitan fabric. Functional developments around ports and marinas also belong to this family. Of course, street-corridor effect is inexistent in these areas, and coverage ratio is low but, unlike suburban fabric, houses and other small buildings are almost non-existent and culs-de-sac are rare: the street network is highly connective in order to ease vehicular traffic in pedestrian unfriendly environments.

The last two families (No. 8 and 9) characterize the less developed areas of the metropolitan space. Most of them are made of natural land and, more seldom, agricultural land. Buildings are nevertheless always present here and there and the roads and trails (more than the streets) serving these areas are still a channel for pedestrian movement and visual perception. Like for suburban fabrics, a difference can be made between non-urbanized space in the hills and in the plains (No. 8), where landscapes are more open and smooth, and both buildings and individual houses can punctuate the landscape, and natural space in the mountains (No. 9), with long, winding and steep street segments, high terrain slopes, rare small houses, and sometimes panoramic visual fields. Once again, the former are more present in the western section of the Riviera, the latter are more frequent in the eastern section, where the Prealps almost tumble into the sea. Good $21 \%$ of street segments in the metropolitan area are characterized by these two families of essentially non-urban fabrics. If calculated in street length, their share would be significantly higher, as the longest street segments are to be found here. We will also remark that metropolitan parks with organized networks of long pathways are to be found in these two families, whether in the plain or in the mountains. On the contrary, most urban public gardens, because of their higher connectivity, shorter segments and presence of technical facilities are much more often classified in the family of the connective, artificial fabrics even if, for once, they are much more a pedestrianfriendly than a car-friendly environment.

The spatial Organization of the French Riviera

When projected in geographic space the clusters identify well defined, large spatial patterns of connected spatial units making up peculiar morphological regions in the metropolitan area. A few sectors mix two families of similar urban fabrics (No. 1 and 2, No. 3 and 4, No. 5 and 6, No. 8 and 9). Areas of fine-grained patchwork of several urban fabrics are particularly rare. MFA makes here a contribution to the long felt need for more clarity in the identification of morphological regions (Larkham and Morton 2011).

Figure 4 maps the western section of the French Riviera, around the cities of Antibes, Cannes and Grasse (up) and the central section, around the city of Nice (down). The old city centers of Antibes, Nice and Cannes (but even Grasse in the hinterland) are clearly distinguishable in brown color (family No.1), surrounded by traditional urban fabric of the 
late XIX and early XX (family No.2). More peripheral urban sectors belong to families No.3 and No.4, often in opposite sectors of urban development, whereas vast suburban areas (mainly family No.5 around Antibes and Cannes, family No.5 west of Nice, but No.6 north and east of Nice) border the outskirts of the main cities. The traditional fabrics of smaller villages in the close hinterland are identifiable as islands within suburbia. We can also observe the importance of suburban fabrics of family No.5 in the capes. Finally, connective artificial fabrics correspond to the urban fringe belts west of Nice and north of Antibes, but also to the technical space around ports and airports, and to the core of the technological park of Sophia Antipolis (where a few modern developments also recreated the morphological characteristics of traditional urban fabrics). The results found for the city of Nice, showing the substantial continuity of traditional urban fabrics of the plain from the most central area towards the North and the East, as well as the relative importance of modern discontinuous urban fabrics in the western section of the city, in the north and on the hill of Cimiez, are in good agreement with more qualitative expertbased analysis carried out by Graph (2014).

The striking similarities in the spatial organization of morphological regions around the coastal cities of Cannes, Antibes, Cagnessur-Mer, Nice, Monaco and Menton brought us to the conclusion that, despite the local specificities (like the planned urban grid of Nice or the constrained high-rise developments of Monaco), the cities of the French Riviera show a common genotype of spatial organization. This is represented through the simplified diagram of Figure 5. The archetypical Riviera city has a concentric double core of inner old city and traditional pre-modern urban fabric. Discontinuous irregular fabrics and modern discontinuous fabrics develop on well-defined and opposed sectors around them. Further out, different forms of suburbs were added in the last fifty years, with specific forms on the prestigious capes. A further belt of more or less topographically constrained natural space lies around the suburbs. However, the spatial organization of the metro-politan area cannot be understood without taking into consideration the three following aspects:
1. Old villages are scattered in the immediate hinterland. When they are small cities (like Grasse or Vence), they show the same juxtaposition of urban forms already found for the coastal cities.

2. Connective artificial fabrics are a very peculiar new urban form of the metropolitan development of the last fifty years. They are to be found in the interstices of the urban periphery and suburbs, along main transportation axis and sometimes on the very coastal line, connecting ports, airports, shopping malls and other large urban facilities.

3. This scheme is a module repeated several times within the metropolitan area around each major coastal city. The spatial organization of the French Riviera metropolitan area is thus a doubly self-similar structure: repetition of the same module, on a similar scale, along the coast and repetition of miniature version of it in the close hinterland.

A few exceptional areas depart from this scheme. This is namely the case for the Sophia-Antipolis technological park, north of Antibes. Here, a large matrix of artificial, connective urban fabrics is surrounded by natural areas. Within it, we find enclaves of modern discontinuous urban fabrics and of more traditional urban fabrics with adjoining buildings. The morphological region of the technological park is thus more a mosaic of these three families than a homogeneous area characterized by the presence of a single type of urban fabrics.

Finally, apart from a few noticeable exceptions, the metropolitan area is structured by an urban scheme mixing concentric belts and sectors, interwoven with new connective fabrics, that repeats itself several times from east to west, with some self-similarity at different scales.

\section{Conclusions}

MFA is an inferential data-driven procedure of urban fabric analysis coupling the calculus of morphological indicators, geostatistical analysis of spatial patterns and Bayesian clustering. Applied to the French Riviera, MFA 
proved capable of identifying nine families of urban fabrics which are particularly well defined in terms of morphological characteristics. Projected in geographic space, each family of urban fabrics stretches coherently over a whole morphological region. The spatial organization of morphological regions of the coastal cites of the French Riviera follows the same archetypical genotype, mixing concentric belts and sectors, interwoven by new connective fabrics. The whole metropolitan area is finally an assemblage of several city modules with some self-similarity at different scales.

These results could not be obtained through manual calculations or expert-based procedures given the spatial extent of the case study. At the same time, this data-driven bottom-up procedure is not intended to supersede traditional expert-base analysis of urban fabric. Rather, it should be considered as a complementary tool for the analysis of urban forms within a large metropolitan area. The power of this method consists in allowing the analysis of urban complexity of extended areas, identifying key factors to characterize urban fabrics diversity and geographic distribution of significant spatial patterns. Moreover, MFA was conceived as a geoprocessing approach assuming the pedestrian viewpoint on urban fabrics. Morphological indicators where calculated to describe form elements as they can be observed by the pedestrian moving on the street and further geoprocessing analyses use the values of these indicators. In this respect, the urban fabrics identified through MFA analyses are potentially to be crossanalyzed with socioeconomic phenomena which could be related to urban form (like retail activity, crime, housing choice, neighborhood satisfaction, etc.) more than with environmental phenomena (pollution, micro-climate, urban ecosystems, etc.) that are not linked to human perception and exploration of urban space.

Other indicators of urban perception could then be integrated in the MFA analysis, like isovist indicators (Benedikt 1979). Indeed, Batty (2001) describes visual fields modelled through isovists as the interaction of geometry and movement, two founding principles of MFA approach. Stylistic and typological descriptors of observable buildings and of street furniture could also be added, establishing bridges both with researches on urban ambiances (Thibaud 2002) and on typo-morphological analyses. If the goal of the research is not urban form as perceived by humans, MFA approach, with its three defining phases of analysis, can also be applied on other partitionings of urban space, like city-blocks.

A different direction of research would be to cross-analyze "objective" urban forms identified through MFA with "subjective" urban forms in individual and social cognition and representation (Lynch 1980, Cauvin 1984). Morphological regions, as well, i.e. the spatial extent of a given recognizable urban form, could be characterized by their representation in mental maps and their semantical descriptions in textual data. Finally, a diachronic dimension should be added to MFA analysis in order to better support research on urban morphological processes on vast metropolitan areas, a research direction already initiated by Pinho and Oliveira (2009). 


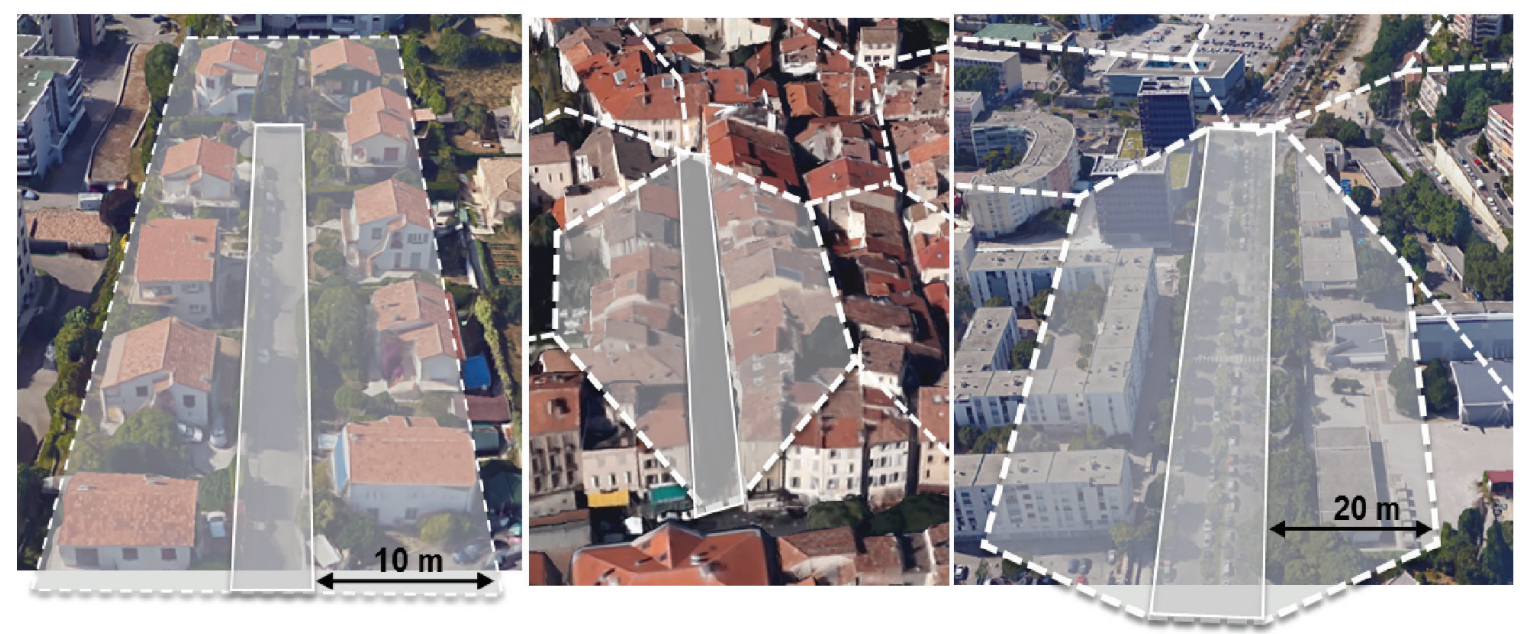

Figure 1. The spatial units of the analysis: proximity bands around street segments.
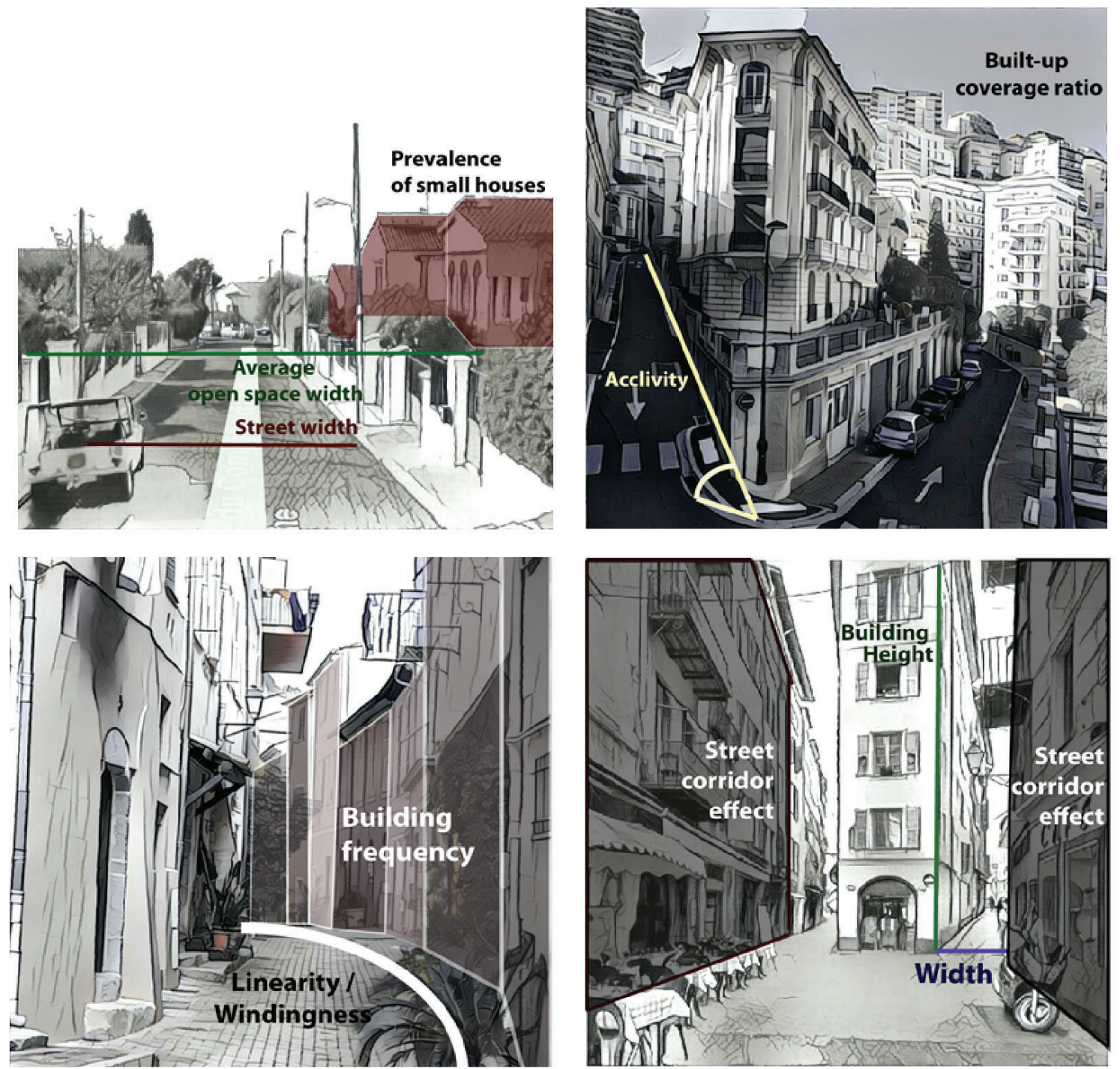

Figure 2. Morphological indicators from the pedestrian point of view. 


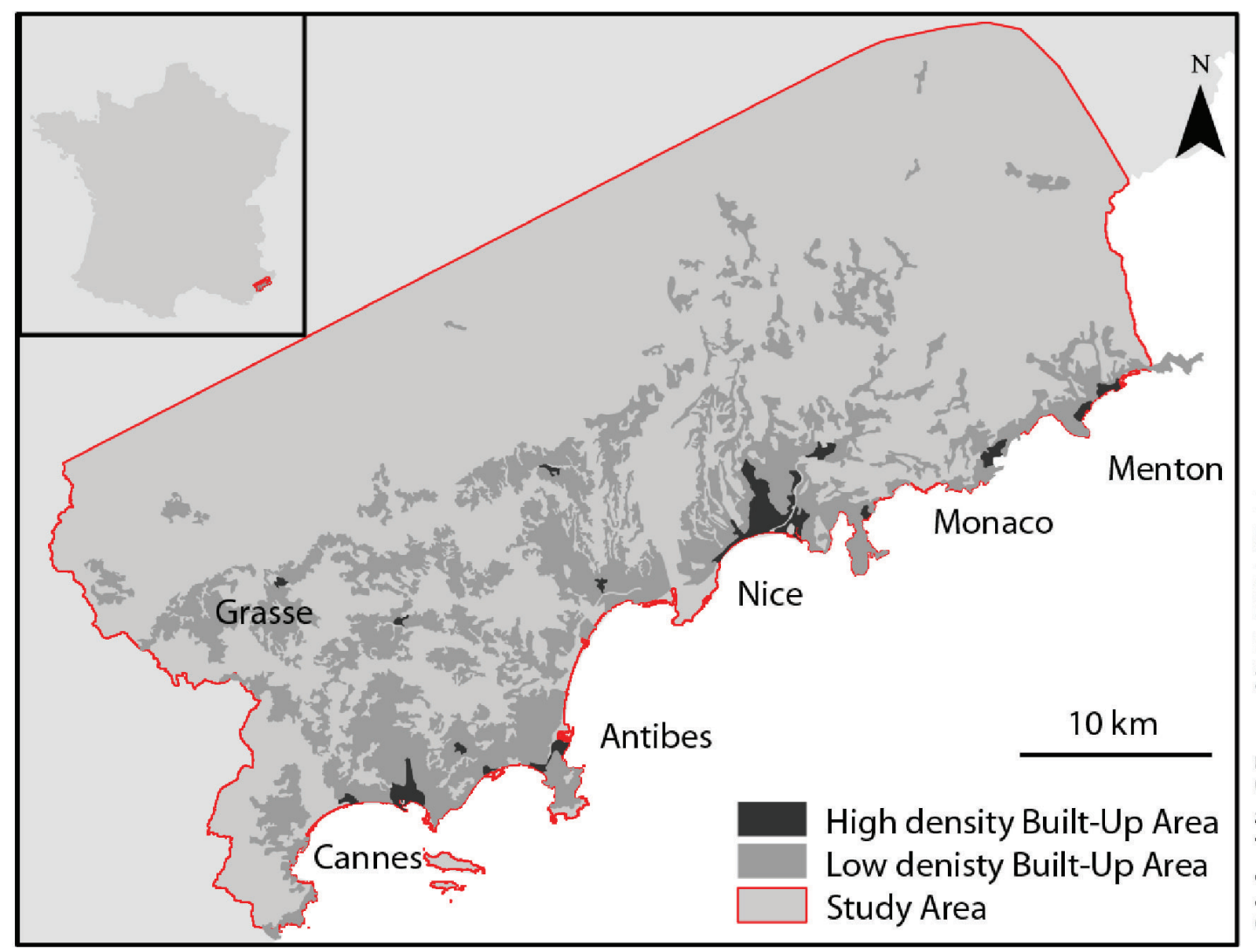

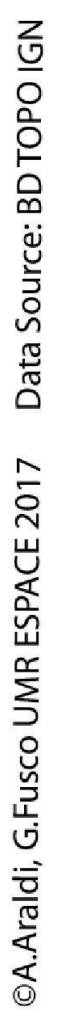

Figure 3. The French Riviera Metropolitan Area.
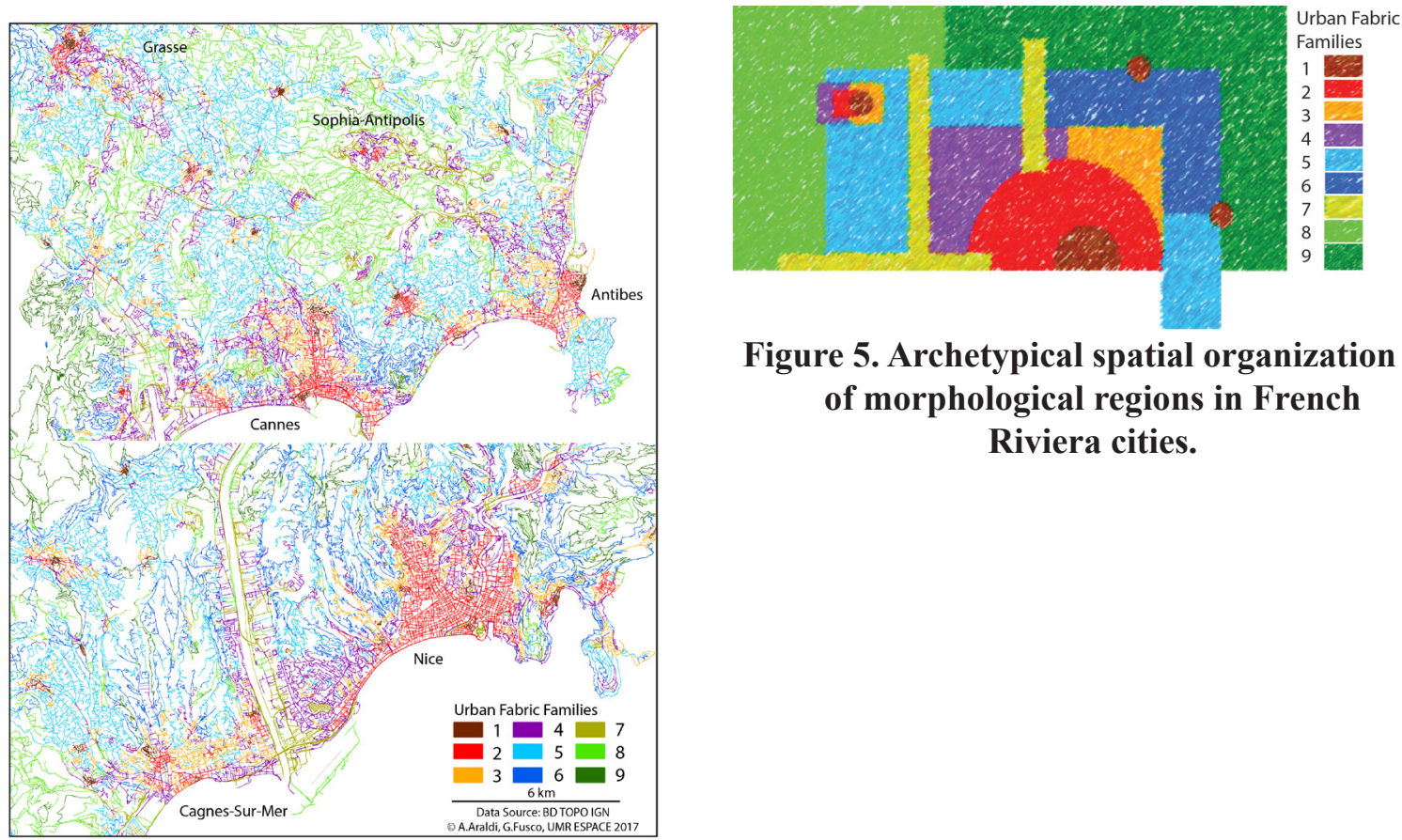

Figure 5. Archetypical spatial organization of morphological regions in French Riviera cities.

Figure 4. Families of urban fabrics projected in geographic space. 


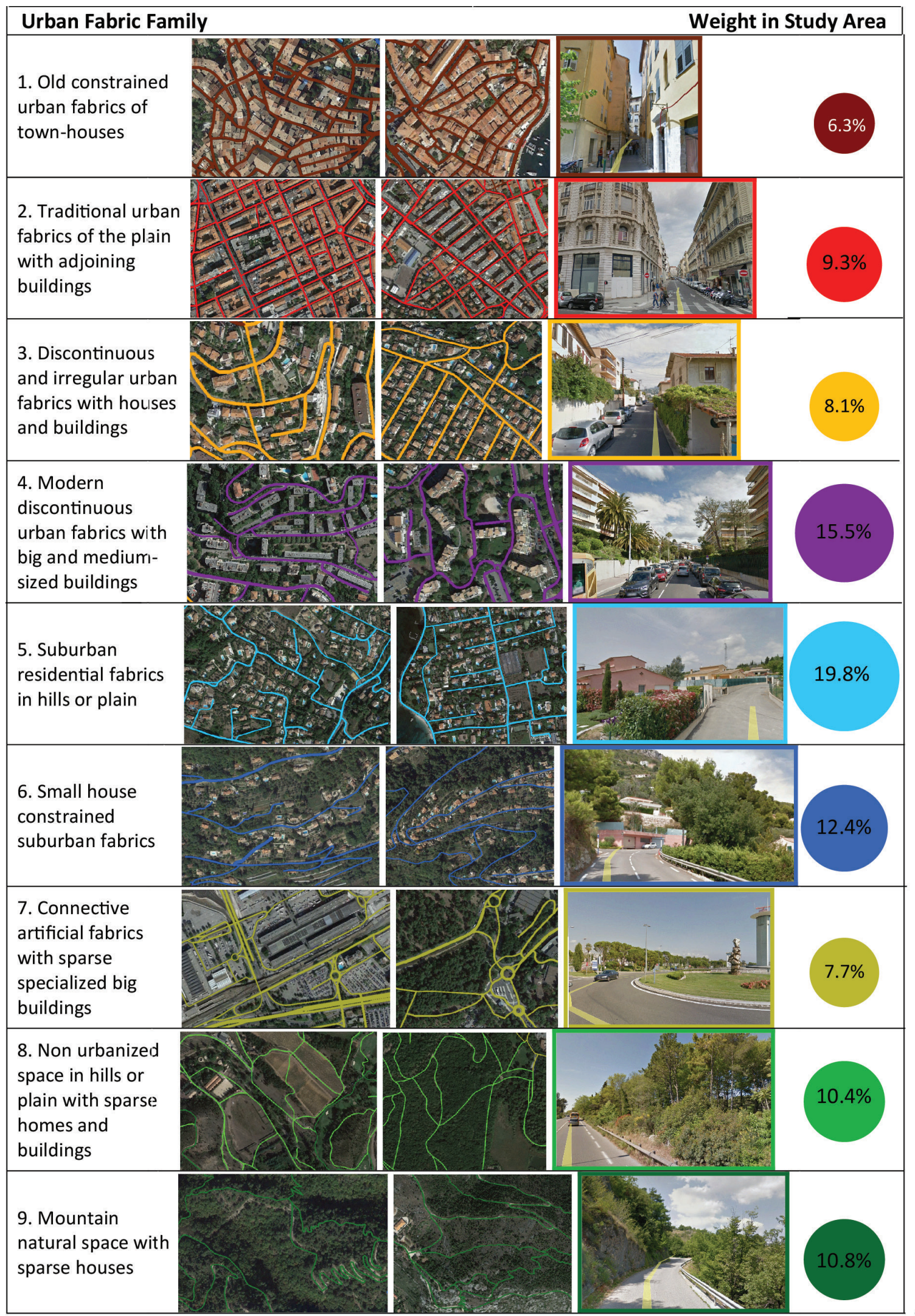

Table 1. Families of Urban Fabrics on the French Riviera. 


\section{References}

Araldi A., Fusco G. (2017) 'Decomposing and Recomposing the City from the Pedestrian Point of View: A New Methodology for Urban Fabric Recognition and Characterization', in G. Borruso et al. (Eds.) ICCSA 2017 Proceedings (in press).

Ascher, F. (1995) Métapolis ou l'avenir des villes. (Odile Jacob, Paris).

Batty M (2001) 'Exploring isovist fields: space and shape in architectural and urban morphology', Environment and Planning B: Planning and Design, 28, 123-150.

Benedikt, M. (1979) 'To Take Hold of Space: Isovists and Isovist Fields', Environment and Planning B, 6(1) 47-65.

Berghauser Pont, M., Haupt, P. (2010) SPACEMATRIX, Space, Density and Urban Form. (NAi Publishers, Rotterdam).

Bernabé A et al. (2013) 'Classification automatique des tissus urbains par la méthode des nuées dynamiques', 31e Rencontres AUGC, Cachan, France, http:// augc2013.ens-cachan.fr/ Data/Articles/ Contribution1150.pdf

Borie A, Denieul F (1984) Methode d'analyse morphologique des tissus urbains traditionnels, $\quad \mathrm{http} / /$ unesdoc.unesco. org/images $/ 0006 / 000623 / 062310 \mathrm{fb} . p d f$ (UNESCO, Paris).

Caniggia G, Maffei G (2008(1979)) Lettura dell'edilizia di base. (Alinea, Firenze).

Cauvin C. (1984) Espaces cognitifs et transformations cartographiques. Les conditions de la comparaison des espaces cognitifs : de la carte aux configurations ; exemples de l'espace urbain strasbourgeois, Thèse de Doctorat d'État, Université de Strasbourg, Micro-fiches à Lille ${ }^{\circ} 8509$ 2134

Frankhauser P. (1994) La fractalité des structures urbaines. (Anthropos, Paris).

Fusco G (2016) 'Beyond the Built-up Form / Mobility Relationship: Spatial Affordance and Lifestyles'. Computer, Environment and Urban Systems, 60: 50-66.

Giannopoulou M et al. (2014) 'Using GIS to Record and Analyse Historical Urban Areas'. Tema. Journal of Land Use, Mobility and Environment, 4-2014, 43-47.
Gil J., Beirão J.N., Montenegro, N., Duarte J. (2012) 'On the discovery of urban typologies: data mining the many dimensions of urban form', Urban Morphology, 16(1), 27-40.

Graff, Ph. (2000) L'exception Urbaine. Nice : de la Renaissance au Consiglio d'Ornato. (Parenthèses, Marseille).

Graff, Ph. (2013). Une ville d'exception. Nice, dans l'effervescence du $20^{\circ}$ siècle. (Serre, Nice).

Hillier, B. (1996) Space is the machine. (Cambridge University Press, Cambridge).

Hillier B., Hanson J. (1984) The social logic of space. (Cambridge University Press, Cambridge).

Knox P. (1992) "The Packaged Landscape of Post-Suburban America", in J. Whitehead and P. Larkham (Eds.) Urban Landscapes. International Perspectives. (London, Routledge) 207-226

Larkham PJ, Morton N (2011) 'Drawing lines on maps: morphological regions and planning practices', Urban Morphology, 15:133-151

Levy A. (1999) 'Urban morphology and the problem of the modern urban fabric: some questions for research', Urban Morphology, $3(2), 79-85$

Levy, A. (2005) 'Formes urbaine et significations: revisiter la morphologie urbaine', Espace et sociétés, 122(4), 25-48.

Long N, Kergomard C (2005) 'Classification morphologique du tissu urbain pour des applications climatologiques. Le cas de Marseille'. Revue Internationale de Géomatique, 15(14), 487-512.

Lynch K. (1960) The Image of the City. (MIT Press, Cambridge, MA).

Marshall, S. (2005) Streets and patterns: the structure of urban geometry. (Routledge, London).

Okabe, A. Sugihara, K. (2012) Spatial Analysis along Networks: Statistical and Computational Methods. (John Wiley, London).

Panerai Ph., Castex J., Depaule J.-Ch. (1997) Formes urbaines. De l'îlot à la barre. (Parenthèses, Marseille).

Pinho P., Oliveira V. (2009) 'Cartographic analysis in urban morphology', Environment 
and Planning B: Planning and Design, 36, 107-127.

Puissant A et al. (2010) 'Classification des tissus urbains à partir de données vectorielles - Application à Strasbourg', SAGEO 2010 Proceedings, Toulouse, 198-211.

Thibaud J.-P. (2002) 'L'horizon des ambiances urbaines', Communications, 73, 185-201.

Thomas I et al. (2007) 'Fractal dimension versus density of built-up surfaces in the periphery of Brussels', Papers in Regional Science, 86, 287-308.

Yamada I., Thill J.C. (2010) 'Local indicators of network-constrained clusters in spatial patterns represented by a link attribute', Annals of the Association of American Geographers, 100(2), 269-285.

\section{Acknowledgements.}

This research was carried out thanks to a research grant of the Nice-Côte d'Azur Chamber of Commerce and Industry (CIFRE agreement with UMR ESPACE). 